\title{
Avaliação econômica e desempenho de machos e fêmeas Canchim em confinamento alimentados com dietas à base de silagem de milho $\mathrm{e}$ concentrado ou cana-de-açúcar e concentrado contendo grãos de girassol ${ }^{1}$
}

\author{
Alexandre Rodrigo Mendes Fernandes ${ }^{2}$, Alexandre Amstalden Moraes Sampaio ${ }^{3}$, Wignez \\ Henrique $^{4}$, Dilermando Perecin ${ }^{5}$, Emanuel Almeida de Oliveira ${ }^{6}$, Rymer Ramiz Túllio ${ }^{7}$
}

${ }^{1}$ Parte da tese de Doutorado do primeiro autor

2 Doutorando em Zootecnia - FCAV/Unesp. Bolsista Fapesp.

${ }^{3}$ Departamento de Zootecnia - FCAVIUnesp. Bolsista CNPq

${ }^{4}$ APTA - São José do Rio Preto.

${ }^{5}$ Departamento de Ciências Exatas - FCAV/Unesp.

${ }^{6}$ Acadêmico de Zootecnia - FCAV/Unesp. Bolsista CNPq/Pibic.

${ }^{7}$ Embrapa/CPPSE - São Carlos, SP.

RESUMO - Objetivou-se avaliar os efeitos do fornecimento de dietas com silagem de milho ou com cana-de-açúcar + grãos de girassol e a influência da condição sexual do animal sobre o desempenho de bovinos jovens em confinamento e os resultados econômicos desse sistema de produção. Foram utilizados 30 animais Canchim (dez machos não-castrados, dez machos castrados e dez novilhas), com 15 meses de idade e $289 \mathrm{~kg}$ de peso corporal (PC), mantidos em baias individuais durante 105 dias. Todos os animais foram pesados no início do experimento e a cada 35 dias e, ao final do confinamento, foram abatidos em frigorífico comercial para realização das medidas de características de carcaça. Os machos não-castrados apresentaram maior ingestão de nutrientes em comparação às fêmeas, tanto em valores absolutos quanto em valores relativos ao PC. Os machos castrados apresentaram valores intermediários e não diferiram dos não-castrados e das fêmeas. Os machos nãocastrados apresentaram maior ganho de peso diário e desenvolvimento muscular, representado pela maior área de olho-delombo. Também foram mais eficientes quanto à conversão alimentar e ao rendimento de carcaça. Não houve efeito das dietas sobre a ingestão de nutrientes, à exceção do EE, que foi maior para a dieta com cana-de-açúcar + semente de girassol, com mais teor desse nutriente. As dietas também não influenciaram o desempenho dos animais. A dieta com silagem de milho mostrou-se economicamente mais viável para terminação de bovinos jovens em confinamento. Os machos não-castrados são os mais adequados para exploração de bovinos jovens em confinamento, independentemente da dieta.

Palavras-chave: Canchim, ganho de peso, novilhas, novilhos, rentabilidade

\section{Economic evaluation and performance of feedlot male and female Canchim fed corn silage and concentrate or sugar cane plus concentrate with sunflower seed based diets}

\footnotetext{
ABSTRACT - The objective of this experiment was to evaluate the effects of diets with corn silage or with sugar cane + sunflower seed and influence of sexual categories of fedlot young cattle on the performance and economic results of this production system. Thirty animals of Canchim breed (10 young bulls, 10 castrated males and 10 females) averagfing 15 months old and $289 \mathrm{~kg}$ BW were housed in individual stalls, for 105 days and weighted in the beginning of the experiment and every 35 days. At the end of the feedlot, all the animals were slaughtered in commercial frigorific and measures of carcass characteristics were made. Young bulls showed higher nutrient intakes as compared to females, in absolute values and in relation LW values. The castrated males presented intermediary values, not differing from young bulls and females. Young bulls presented higher daily weight gain and muscular development, represented by the largest rib eye area. They were also more efficient as for feed conversion and carcass yield. No effect was observed for diets on the ingestion of nutrients, except for EE, that was higher for the diet with sugarcane + sunflower seed, with more of this nutrient. Diets also did not influence performance of the animals. Diet with corn silage showed more economically viable to raised young cattle in fed lot finishing. Young bulls were the animals more adequate for the exploration of young cattle in feedlot, independently of diet.
}

Key Words: Canchim, heifers, profitability, steers, weight gain 


\section{Introdução}

A cada ano, o agronegócio brasileiro consolida sua importante posição na economia, como resultado do avanço tecnológico, do incremento na produtividade e da ocupação de novas áreas. Ainda que em 2004 tenha ocorrido desaceleração da agropecuária nacional, com retração de 0,87\% do Produto Interno Bruto (PIB) do setor primário em virtude da redução nos preços pagos ao produtor, essa situação não reflete a média atual do desempenho do setor, cujo crescimento foi de 6,54\% em 2003. Entre seus produtos, destaca-se a produção de carne, que representou em 2004 em torno de 40,6\% do PIB agropecuário (CNA, 2005).

A produção de carne no Brasil tem crescido significativamente, observando-se que, a partir de 1990, com a globalização da economia e a abertura dos mercados, intensificou-se ainda mais o processo de modernização da atividade agropecuária, em decorrência do aumento da competitividade e da forte pressão da relação desfavorável entre os preços de insumos e de produtos.

Nesse contexto econômico, verifica-se interesse crescente em estratégias que proporcionem melhores resultados de eficiência produtiva e qualidade dos produtos, pois a atividade pecuária tende a ser mais uma atividade empresarial, afastando-se do modelo extrativista e aproximando-se da intensificação total (Euclides Filho, 2004).

De acordo com Burgi (2001), o confinamento pode ser visto como estratégica para o pecuarista ganhar em escala no seu sistema de produção e obter qualidade em seus produtos. Esse autor apontou alguns benefícios do confinamento, como o adiantamento de receitas e a aceleração do giro de capital, a redução da lotação das pastagens durante a seca, o aumento da escala de produção e da produtividade da propriedade e o abate de animais mais jovens. Entretanto, a adoção de manejo intensivo visando maior produtividade envolve diversos fatores, como o potencial genético dos animais e estratégias de alimentação que atendam às exigências nutricionais.

Nesse contexto, a cana-de-açúcar como alimento volumoso para bovinos em confinamento, apesar de seu baixo valor nutricional, quando corretamente associada a concentrados, pode ser uma alternativa, principalmente em regiões sucroalcooleiras. Segundo Hernandez (1998), devem ser considerados ainda a alta produtividade, o menor custo por unidade de MS produzida e o pico de produção no período de escassez de pastagens. Para suprir as deficiências nutricionais da cana-de-açúcar, os grãos de oleaginosas, como os de girassol (Helianthus annuus), são potencialmente eficientes, por apresentarem alto teor de proteína e óleo de excelentes características nutricionais. Essa cultura apresenta ainda características agronômicas importantes, como grande adaptabilidade às diferentes condições edafoclimáticas e baixa incidência de pragas e doenças, sendo também mais resistente à seca que as culturas de milho e de sorgo (Bett, 2002).

Considerando o potencial de desempenho dos animais a serem explorados em confinamento, Macedo et al. (2001) relataram que a utilização de machos não-castrados tem aumentado substancialmente, em virtude do maior ganho de peso, da melhor conversão alimentar, da menor quantidade de gordura visceral, da maior área de olho-de-lombo e da maior porção comestível. Por outro lado, a taxa de abate de fêmeas no Brasil permanece superior a 40\% (Restle et al., 2001), comprovando a importância desta categoria para a oferta de carne no mercado.

Este trabalho foi realizado para avaliar o efeito da adição de grãos de girassol em dietas à base de cana-deaçúcar e da condição sexual de bovinos jovens sobre o desempenho e a viabilidade econômica da terminação em confinamento.

\section{Material e Métodos}

Oexperimento foi desenvolvido no Setor de Bovinocultura de Corte da Faculdade de Ciências Agrárias e Veterinárias/ Unesp, em Jaboticabal, SP, que conta com 30 baias individuais de $16 \mathrm{~m}^{2}$, com piso concretado, parcialmente cobertas e providas de bebedouros. Em dias alternados, foram realizadas a limpeza dos bebedouros e a retirada do esterco das baias.

Foram utilizados 30 animais da raça Canchim (dez machos não-castrados, dez machos castrados e dez fêmeas), provenientes do rebanho da própria faculdade, com aproximadamente 15 meses de idade e peso corporal (PC) de $289 \pm 16$ kg. Todos os animais receberam os tratamentos sanitários (banho carrapaticida e everminação) antes do início do experimento. Os animais foram adaptados às instalações, ao manejo e às dietas durante 21 dias. Após este período, foram alocados aleatoriamente nas baias.

Foram testadas duas dietas balanceadas para serem isoprotéicas e isoenergéticas (uma delas composta de canade-açúcar como volumoso exclusivo e concentrado contendo grãos de girassol), com 89,2\% de MS, 29,6\% de PB, 38,0\% de EE e $20,3 \%$ de FDN. A dieta controle, formulada com silagem de milho e farelo de soja, foi escolhida por ser convencionalmente utilizada para terminação de bovinos jovens em confinamento.

As dietas experimentais, cujas composições são apresentadas na Tabela 1, foram formuladas para proporcionar ganho de $1,3 \mathrm{~kg} /$ dia, pelo sistema $\mathrm{RLM}^{\circledR} /$ Esalq-USP, e balanceadas de acordo com o sistema CNCPS, desenvolvido 
Tabela 1 - Composição bromatológica dos volumosos e formulação inicial (\% MS) das dietas experimentais

Table 1 - Chemical composition of forage and initial formulation (\% of DM) of the experimental diets

\begin{tabular}{|c|c|c|c|}
\hline \multirow{3}{*}{$\begin{array}{l}\text { Volumoso } \\
\text { Forage }\end{array}$} & \multicolumn{3}{|c|}{$\begin{array}{c}\text { Composição bromatológica (\% MS) } \\
\text { Chemical composition (\% DM) }\end{array}$} \\
\hline & MS & $\mathrm{PB}$ & FDN \\
\hline & $D M$ & $C P$ & $N D F$ \\
\hline Cana-de-açúcar (Sugar cane) & 30,06 & 2,50 & 53,44 \\
\hline \multirow[t]{2}{*}{ Silagem de milho (Corn silage) } & 31,09 & 7,90 & 52,30 \\
\hline & & \multicolumn{2}{|c|}{$\begin{array}{l}\text { Dieta }^{1} \\
\text { Diet }^{1}\end{array}$} \\
\hline \multirow{2}{*}{\multicolumn{2}{|c|}{$\begin{array}{l}\text { Ingrediente } \\
\text { Ingredient }\end{array}$}} & SIL & CNA \\
\hline & & CS & $S C$ \\
\hline \multicolumn{2}{|l|}{ Cana-de-açúcar (Sugar cane) } & - & 40,00 \\
\hline \multicolumn{2}{|l|}{ Silagem de milho (Corn silage) } & 40,00 & - \\
\hline \multicolumn{2}{|l|}{ Grãos de girassol (Sunflower seed) } & - & 11,30 \\
\hline \multicolumn{2}{|l|}{ Farelo de soja (Soybean meal) } & 10,60 & 13,65 \\
\hline \multicolumn{2}{|l|}{ Milho em grão moído (Ground corn) } & 35,50 & 22,15 \\
\hline \multicolumn{2}{|l|}{ Polpa cítrica (Dried citrus pulp) } & 11,00 & 10,00 \\
\hline \multicolumn{2}{|l|}{ Núcleo mineral (Mineral premix) } & 1,00 & 1,00 \\
\hline \multicolumn{2}{|l|}{ Uréia (Urea) } & 0,40 & 0,40 \\
\hline \multicolumn{2}{|c|}{ Bicarbonato de sódio (Sodium bicarbonate) } & 1,50 & 1,50 \\
\hline \multicolumn{4}{|l|}{$\begin{array}{l}\text { Perfil nutricional } \\
\text { Nutritional profile }\end{array}$} \\
\hline \multicolumn{2}{|l|}{ MS (\%) (DM) } & 51,00 & 48,00 \\
\hline \multicolumn{2}{|l|}{$\mathrm{PB}^{2}(C P)$} & 14,00 & 14,05 \\
\hline \multicolumn{2}{|l|}{$\mathrm{NDT}^{2}(\mathrm{TDN})$} & 75,00 & 74,00 \\
\hline \multicolumn{2}{|l|}{$\mathrm{EM}(\mathrm{MJ} / \mathrm{kg} \mathrm{MS})(M E, M J / \mathrm{kg} D M)$} & 11,68 & 11,52 \\
\hline \multicolumn{2}{|l|}{$\mathrm{EE}^{2}$} & 3,10 & 4,10 \\
\hline \multicolumn{2}{|c|}{ Ganho estimado (kg/anim/d) (Estimated gain) } & 1,30 & 1,30 \\
\hline
\end{tabular}

por Fox et al. (1992). As dietas foram reajustadas a cada 35 dias, de acordo com o incremento de PC e a condição sexual, para manter seu nível nutricional e possibilitar o desempenho proposto.

A variedade de cana-de-açúcar utilizada foi a forrageira IAC 86-2480, de boa produtividade, alto teor de açúcar e baixo teor de fibra, com grande potencial para alimentação animal (Landell et al., 2002). O corte da cana-de-açúcar foi realizado manualmente, em dias alternados, e a picagem (partículas de aproximadamente $2 \mathrm{~cm}$ ) em picadeira estacionária imediatamente antes do fornecimento aos animais. Os ingredientes utilizados na composição dos concentrados foram triturados em moinho com peneira de crivos de $2 \mathrm{~mm}$ e, posteriormente, a mistura foi preparada em misturador horizontal por 5 minutos.

As dietas foram fornecidas à vontade, na forma de ração completa, divididas em duas refeições (8 e 14h), calculando-se $40 \%$ da quantidade diária no primeiro horário e $60 \%$ no segundo. Durante todo o período experimental, as quantidades fornecidas foram ajustadas para permitir $10 \%$ de sobras em relação ao total consumido no dia anterior, como descrito por Sampaio et al. (1998). As sobras foram retiradas a cada dois dias, agrupadas em períodos de 35 dias e acondicionadas em congelador a $-20^{\circ} \mathrm{C}$. Ao final de cada período, as amostras foram encaminhadas ao Laboratório de Ruminantes da FCAV/Unesp para análise dos teores de MS, PB, EE, FDN e FDA, de acordo com metodologia descrita pela AOAC (1995), permitindo estimar a ingestão de nutrientes pelos animais.

Além do período de adaptação, os animais foram mantidos em confinamento por 105 dias, sendo pesados a cada 35 dias, após jejum de sólidos por 15 horas, segundo recomendações de Sampaio et al. (1998), e monitorados por ultra-som.

Para avaliação ultra-sonográfica, os animais foram imobilizados em tronco individual e tosquiados à altura de pelame de $1 \mathrm{~mm}$, na região entre a $12^{\underline{a}}$ e a $13^{\underline{a}}$ costela. O sítio de avaliação foi recoberto por uma camada delgada de óleo de soja, imediatamente antes da tomada de imagens, a fim de garantir maior contato acústico do stand off da probe com a pele do animal e permitir máxima resolução nas imagens (Fernandes et al., 2004). Mediante as imagens tomadas ao longo do confinamento, foram avaliados os ganhos em área de olho-de-lombo (AOL) e em espessura de gordura subcutânea (EGS) para estimativa do desenvolvimento muscular e do grau de acabamento dos animais. A diferença entre a medida final e inicial, realizada por ultrasom, foi utilizada para o cálculo do ganho de área de olhode-lombo e ganho de gordura subcutânea.

Depois de atingirem o ponto de acabamento (16 arrobas para os machos e 15 arrobas para as fêmeas e $3 \mathrm{~mm}$ de gordura subcutânea, estimada por ultra-som), os animais foram transportados a um frigorífico comercial. No dia seguinte, após jejum de sólidos de 24 horas, foram abatidos segundo os procedimentos de atordoamento por concussão cerebral utilizando-se pistola de ar comprimido e posterior sangria por secção da jugular.

No abate, foram obtidos os pesos de carcaça quente e o rendimento de carcaça, obtido pela relação entre o peso de carcaça quente e o peso de abate, em porcentagem. Após resfriamento por 24 horas em câmara frigorífica a $4^{\circ} \mathrm{C}$, as carcaças foram novamente pesadas para obtenção do peso de carcaça fria.

Posteriormente, foi retirada da meia-carcaça esquerda uma secção do músculo Longissimus dorsi, entre a 12aa e a $13^{\mathrm{a}}$ costela, para realização das medidas de área de olho-delombo e da espessura de gordura subcutânea em laboratório, permitindo maior precisão das mensurações. Para a medida da área de olho-de-lombo, foi realizado um corte transversal na região entre a $12^{\mathrm{a}}$ e a $13^{\underline{a}}$ costela, de modo a expor 0 músculo. Em seguida, foi retirado o decalque da peça em 
papel vegetal e a área foi medida com planímetro de bancada. A espessura de gordura subcutânea foi medida no terceiro quarto do músculo, a partir da coluna vertebral, perpendicularmente ao músculo Longissimus dorsi, com o auxílio de uma régua de precisão, segundo recomendações de Tullio (2004).

O delineamento experimental utilizado foi o inteiramente casualizado, em esquema fatorial $3 \times 2$ (condições sexuais $\times$ dietas). As variáveis foram avaliadas por meio de análise de variância verificando-se a existência ou não da interação sexo $\times$ dieta. Em seguida, as médias foram comparadas pelo teste Tukey a 5\% de probabilidade (Sampaio, 2002).

\section{Resultados e Discussão}

O consumo de nutrientes diferiu entre os animais com condições sexuais diferentes, sendo maior para os machos em relação às fêmeas $(\mathrm{P}<0,05)$ (Tabela 2$)$. Os machos castrados apresentaram valores intermediários e não diferiram dos outros grupos. O mesmo não foi observado quando avaliados os consumos em relação ao PC, pois não foram registradas diferenças.

A ingestão de nutrientes, exceto EE, não diferiu $(\mathrm{P}>0,05)$ entre as dietas. Uma vez que a ingestão de MS foi semelhante, este resultado reflete concentração de EE 32\% superior na dieta com cana-de-açúcar, o que resultou em maior ingestão diária desse nutriente (kg/animal). Foi observada ainda interação significativa de tratamentos para dieta e condição sexual (Tabela 3). Esse comportamento se repetiu quando a ingestão de EE foi expressa em relação ao PC, sendo observadas maiores $(\mathrm{P}<0,05)$ ingestões nos animais alimen- tados com a dieta à base de cana-de-açúcar e grãos de girassol no concentrado.

Segundo Church (1988), quantidades elevadas de lipídeos na dieta de ruminantes podem prejudicar a ingestão de MS, pois afetam negativamente a digestão das frações fibrosas, em virtude de seu efeito inibidor das bactérias celulolíticas, o que não foi evidenciado neste trabalho, no qual as diferenças de ingestão estiveram relacionadas às condições sexuais.

De acordo com o NRC (1996), a condição sexual tem efeito limitado sobre a ingestão de alimentos. O grau de maturidade fisiológica, representado pela proporção de tecido adiposo, aparentemente exerce maior influência sobre esta característica, de modo que, para cada ponto percentual de acréscimo na gordura corporal, ocorre diminuição de 2,7\% no consumo de MS. Nesse sentido, as novilhas em determinada idade efaixa de peso, são fisiologicamente mais maduras que os machos, castrados e não-castrados, e podem apresentar menor ingestão de alimento.

Não foram observadas diferenças $(P>0,05)$ entre as dietas quanto à ingestão das frações fibrosas FDN e FDA. Este resultado provavelmente está relacionado à variedade de cana-de-açúcar utilizada (forrageira IAC 86-2480), que, de acordo com Landell et al. (2002), apresenta maior digestibilidade em comparação às variedades industriais comumente utilizadas na alimentação de bovinos em confinamento. Silva et al. (2005) observaram, em ensaio de digestibilidade in vitro, que essa variedade apresenta coeficientes de digestibilidade da MS, FDN e FDA 6, 11 e $8,5 \%$ superiores, respectivamente, em comparação à variedade industrial RB 83-5453, muito utilizada na alimentação de ruminantes.

Tabela 2 - Ingestão de nutrientes por bovinos Canchim de diferentes condições sexuais alimentados com dietas à base de silagem de milho e concentrado ou cana-de-açúcar e concentrado contendo grãos de girassol

Table 2 - Nutrient intake for Canchim cattle of different sexual categories fed corn silage and concentrate based diet or sugar cane and concentrate containing sunflower grains

\begin{tabular}{|c|c|c|c|c|c|c|c|c|}
\hline Item & & $\begin{array}{l}\text { ição sex } \\
\text { lal catego }\end{array}$ & & & & & & \\
\hline $\begin{array}{l}\text { Ingestão diária } \\
\text { Daily intake }\end{array}$ & $\begin{array}{c}\mathrm{MNC} \\
I M\end{array}$ & $\begin{array}{l}\text { MC } \\
C M\end{array}$ & $\begin{array}{l}\mathrm{FM} \\
F M\end{array}$ & F & $\begin{array}{l}\text { SIL } \\
\text { CS }\end{array}$ & $\begin{array}{c}\mathrm{CNA} \\
\mathrm{SC}\end{array}$ & $\mathrm{F}$ & CV (\%) \\
\hline $\begin{array}{l}\text { MS } \\
D M\end{array}$ & $9,05 a$ & $8,2 \mathrm{ab}$ & $7,61 b$ & $*$ & 8,06 & 8,53 & NS & 13,58 \\
\hline $\begin{array}{l}\text { MS (kg/animal/dia) } \\
\text { DM (kg/animal/day) }\end{array}$ & 2,37 & 2,27 & 2,19 & NS & 2,18 & 2,37 & NS & 12,00 \\
\hline $\begin{array}{l}\mathrm{PB} \text { (kg/animal/dia) } \\
C P \text { (kg/animal/day) }\end{array}$ & $1,39 a$ & $1,25 \mathrm{ab}$ & $1,15 b$ & $*$ & 1,21 & 1,31 & NS & 15,01 \\
\hline $\begin{array}{l}\text { FDN (kg/animal/dia) } \\
\text { NDF (kg/animal/day) }\end{array}$ & $2,69 a$ & $2,43 a b$ & $2,24 b$ & $*$ & 2,58 & 2,32 & NS & 15,45 \\
\hline $\begin{array}{l}\text { FDA (kg/animal/dia) } \\
\text { ADF (kg/animal/day) }\end{array}$ & $1,62 \mathrm{a}$ & $1,46 a b$ & $1,34 b$ & $*$ & 1,42 & 1,53 & NS & 15,45 \\
\hline
\end{tabular}

Médias, na linha, seguidas de letras diferentes diferem $(P<0,05)$ pelo teste Tukey (Means, within a row, followed by different letters differ [P<0.05] by Tukey test).

1 MNC = macho não-castrado; $M C=$ macho castrado; $F M=$ fêmea ( $I M=$ young bull; $C M=$ castrated male; $F M=$ female).

${ }^{2} \mathrm{SIL}=$ dieta convencional à base de silagem de milho e concentrado; $\mathrm{CNA}=$ dieta à base de cana-de-açúcar e concentrado contendo grãos de girassol (CS = conventional corn silage and concentrate based diet; SC = sugar cane and concentrate containing sunflower grains). 
Tabela 3 - Ingestão de EE por bovinos Canchim de diferentes condições sexuais alimentados com dietas à base de silagem de milho e concentrado ou cana-de-açúcar e concentrado contendo grãos de girassol

Table 3 - EE intake for Canchim cattle of different sexual categories fed corn silage and concentrate based diets or sugar cane and concentrate containing sunflower grains

\begin{tabular}{lccc}
\hline Condição sexual $^{2}$ & \multicolumn{2}{c}{ Dieta $^{1}$} & \multirow{2}{*}{$\begin{array}{c}\text { Média CV (\%) } \\
\text { Sexual category }\end{array}$} \\
\cline { 2 - 3 } & SIL & CNA & \\
& CS & SC & \\
\hline
\end{tabular}

Ingestão (kg/animal/dia)

Intake ( $\mathrm{kg} /$ animal/day)

\begin{tabular}{lcccc}
\hline $\begin{array}{l}\text { Machos não-castrados } \\
\text { Young bulls }\end{array}$ & $0,26 \mathrm{Ab}$ & $0,38 \mathrm{Aa}$ & 0,32 & \\
$\begin{array}{l}\text { Machos castrados } \\
\text { Castrated males }\end{array}$ & $0,24 \mathrm{ABb}$ & $0,34 \mathrm{Ba}$ & 0,29 & \\
$\begin{array}{l}\text { Fêmeas } \\
\begin{array}{l}\text { Females } \\
\text { Média }\end{array}\end{array}$ & $0,23 \mathrm{Bb}$ & $0,32 \mathrm{Ba}$ & 0,27 & \\
Mean & 0,24 & 0,34 & - & 15,29 \\
\hline
\end{tabular}

Ingestão (\% PC)

Intake $(\% \mathrm{BW})$

\begin{tabular}{|c|c|c|c|c|}
\hline $\begin{array}{l}\text { Machos não-castrados } \\
\text { Young bulls }\end{array}$ & $0,07 \mathrm{Ab}$ & $0,10 \mathrm{Aa}$ & 0,09 & \\
\hline $\begin{array}{l}\text { Machos castrados } \\
\text { Castrated males }\end{array}$ & 0,07ABb & $0,09 \mathrm{Ba}$ & 0,08 & \\
\hline Fêmeas & $0,06 \mathrm{Bb}$ & 0,09Bа & 0,08 & \\
\hline $\begin{array}{l}\text { Females } \\
\text { Média }\end{array}$ & 0,07 & 0,09 & - & 13,98 \\
\hline
\end{tabular}

Médias, na coluna (maiúsculas) e na linha (minúsculas), seguidas de letras diferentes diferem $(P<0,05)$ pelo teste Tukey (Means, within a column (capital letter) and within a row (small letter), followed by different letters differ $[P<0.05]$ by Tukey test.

$1 \mathrm{SIL}=$ dieta convencional à base de silagem de milho e concentrado; $\mathrm{CNA}=$ dieta à base de cana-de-açúcar e concentrado contendo grãos de girassol (CS = conventional corn silage and concentrate based diet; SC = sugar cane and concentrate containing sunflowergrains).

Os valores das ingestões de MS e PB obtidos foram superiores aos encontrados por Hernandes (1998) em estudo com tourinhos cruzados e mestiços Canchim em confinamento, no qual avaliou a variedade de cana-de-açúcar forrageira CO-413 como volumoso exclusivo. Esse resultado provavelmente está associado ao menor teor de MS (24,27\%) da canade-açúcar utilizada, o que, conseqüentemente, causou redução desta fração na dieta total (39\%).

Cardoso et al. (2004) observaram valor 27\% inferior no consumo absoluto de MS e, quando avaliado o consumo em relação ao PC, essa diferença foi de $47 \%$ em relação ao deste estudo. Os autores não relataram a variedade de cana-deaçúcar utilizada, porém, o teor de FDN encontrado foi 25\% superior ao da variedade IAC 86-2480, utilizada neste trabalho, o que pode ter influenciado negativamente o consumo.

Em estudo realizado por Sampaio et al. (1998) com tourinhos mestiços Canchim terminados em confinamento e alimentados com dietas à base de silagem de milho e concentrados contendo diferentes fontes protéicas (farelo de soja, farelo de algodão ou soja integral), os autores observaram valores de ingestão de MS em relação ao PC em torno de $2,7 \%$, quando avaliadas as dietas contendo farelo de soja ou algodão. Quando considerada a dieta contendo soja integral, o consumo relativo diminuiu para 2,3\%, provavelmente em virtude da presença da fonte protéica oleaginosa, que inibe o consumo naturalmente, prejudicando o desempenho dos animais.

No trabalho realizado por Manzano et al. (1999), novilhas Canchim alimentadas com dietas à base de cana-de-açúcar apresentaram consumo de MS de 8,6 kg/dia, valor 11\% superior ao deste estudo, o que pode estar relacionado ao maior teor de MS da dieta utilizada (69,4\%), embora a relação volumoso:concentrado tenha sido a mesma deste experimento (40:60).

Os machos não-castrados apresentaram ganho de peso $26 \%$ superior $(\mathrm{P}<0,05)$ ao dos machos castrados e ao das novilhas e, mesmo descontando as diferenças numéricas no peso inicial, foram mais pesados ao final do experimento. Os resultados obtidos neste trabalho foram superiores aos observados por Sampaio et al. (1998), em estudo com animais $3 / 4$ Canchim $\times 1 / 4$ Nelore, não-castrados, terminados em confinamento. Esses autores observaram ganho médio de $1,27 \mathrm{~kg} /$ animal.dia, porém, avaliaram dietas com maior proporção de volumoso (60\%) e menor concentração energética.

Tullio (2004) obteve médias de ganho de peso de 0,84 e 1,04 kg/animal/dia em animais castrados e não-castrados, respectivamente. Essa diferença em relação a este trabalho pode estar associada à concentração de NDT das dietas utilizadas por esse autor ( $5 \%$ inferior) e aos tipos biológicos estudados (animais cruzados com maior participação da raça Nelore na composição genotípica).

Macedo et al. (2001) observaram que os animais nãocastrados apresentam maior ganho de peso e melhor eficiência alimentar em relação a machos castrados e fêmeas, como resultado da presença de hormônios esteróides que exercem grande influência no crescimento dos animais. Brondani (2002) observou que a produção de bovinos jovens não-castrados se justifica pelo ganho de peso 10 a 20\% superior e pela eficiência alimentar $16 \%$ melhor, com maior rendimento de carcaça.

Os resultados de conversão alimentar comprovaram que os animais não-castrados foram mais eficientes que os castrados. As fêmeas apresentaram valor intermediário, que não diferiu $(\mathrm{P}>0,05)$ do obtidos em animais de outras condições sexuais. Não foram verificadas diferenças para esta variável quando avaliado o efeito das dietas.

Do mesmo modo, Pádua et al. (2001) obtiveram melhores conversões alimentares quando compararam o desempenho de machos não-castrados ao de machos castrados. Os resultados de conversão alimentar observados neste estudo 
Tabela 4 - Ganho de peso diário (kg/animal/dia), conversão alimentar ( $\mathrm{kg} \mathrm{MS} / \mathrm{kg}$ ganho), taxa de eficiência protéica (kg ganho/kg de proteína ingerida); ganho de área de olho-de-lombo $\left(\mathrm{cm}^{2}\right)$ e ganho de gordura de cobertura $(\mathrm{mm})$ de bovinos Canchim de diferentes condições sexuais alimentados com dietas à base de silagem de milho e concentrado ou cana-de-açúcar e concentrado contendo grãos de girassol

Table 4 - Daily weight gain ( $\mathrm{kg} / \mathrm{animal} /$ day), feed conversion ( $\mathrm{kg}$ DM/kg weight gain), protein efficiency rate ( $\mathrm{kg}$ weight gain/kg intaked protein), rib eye area gain $\left(\mathrm{cm}^{2}\right)$ and backfat thickness gain $(\mathrm{mm})$ by Canchim cattle of different sexual categoried fed corn silage and concentrate based diet or sugar cane and concentrate containing sunflower grains

\begin{tabular}{|c|c|c|c|c|c|c|c|c|}
\hline \multirow[t]{2}{*}{ Item } & \multicolumn{3}{|c|}{$\begin{array}{l}\text { Condição sexual } \\
\text { Sexual category }\end{array}$} & \multicolumn{3}{|c|}{$\begin{array}{l}\text { Dieta }^{1} \\
\text { Diet }\end{array}$} & \multirow[b]{2}{*}{$\mathrm{F}$} & \multirow[b]{2}{*}{ CV (\%) } \\
\hline & $\begin{array}{l}\mathrm{MNC} \\
I M\end{array}$ & $\begin{array}{l}\mathrm{MC} \\
\mathrm{CM}\end{array}$ & $\begin{array}{l}\text { FM } \\
F M\end{array}$ & $\mathrm{~F}$ & $\begin{array}{l}\text { SIL } \\
\text { CS }\end{array}$ & $\begin{array}{c}\text { CNA } \\
\text { SC }\end{array}$ & & \\
\hline $\begin{array}{l}\text { Ganho de peso diário } \\
\text { Daily weight gain }\end{array}$ & $1,65 \mathrm{a}$ & $1,30 \mathrm{~b}$ & $1,32 b$ & $*$ & 1,43 & 1,42 & NS & 13,33 \\
\hline $\begin{array}{l}\text { Conversão alimentar } \\
\text { Feed conversion }\end{array}$ & $5,49 b$ & $6,38 \mathrm{a}$ & $5,81 \mathrm{ab}$ & $*$ & 5,73 & 6,06 & NS & 12,56 \\
\hline $\begin{array}{l}\text { Taxa de eficiência protéica } \\
\text { Protein efficiency rate }\end{array}$ & 1,19 & 1,04 & 1,16 & NS & 1,17 & 1,10 & NS & 14,68 \\
\hline $\begin{array}{l}\text { Ganho de área de olho-de-lombo } \\
\text { Rib eye area gain }\end{array}$ & $37,28 \mathrm{a}$ & $29,94 a b$ & $28,32 b$ & $*$ & 33,79 & 29,90 & NS & 21,63 \\
\hline $\begin{array}{l}\text { Ganho de gordura subcutânea } \\
\text { Backfat thickness gain }\end{array}$ & 2,07 & 3,15 & 3,17 & NS & 2,95 & 2,64 & NS & 46,07 \\
\hline
\end{tabular}

Médias seguidas de letras diferentes na linha diferem $(P<0.05)$ pelo teste Tukey a $5 \%$ de probabilidade (Means followed by different letter in a row differ $(P<0.05)$ by Tukey test). ${ }^{1} \mathrm{SIL}=$ dieta convencional à base de silagem de milho e concentrado; CNA = dieta à base de cana-de-açúcar e concentrado contendo grãos de girasso (CS = convencional corn silage and concentrate based diet; SC = sugar cane and concentrate containing sunflower grains).

foram melhores que os relatados por Sampaio et al. (1998), no entanto, esses autores testaram dietas com maior proporção de volumoso.

Os resultados de ganho de peso diário e conversão alimentar obtidos nas novilhas foram superiores aos observados por Manzano et al. (1999), que obtiveram ganhos médios de $1,08 \mathrm{~kg} /$ dia e conversão alimentar de $8,0 \mathrm{~kg}$ MS $/ \mathrm{kg}$ de ganho de peso diário com novilhas Canchim terminadas em confinamento e alimentadas com dietas à base de canade-açúcar na relação $60 \%$ concentrado e $40 \%$ volumoso.

Estes resultados sugerem que novilhas de raças destinadas à produção de carne podem ser utilizadas em sistemas intensivos de produção, pois apresentam desempenho satisfatório e, embora o valor pago pela carcaça seja 15\% inferior aos dos machos, o preço de aquisição de animais desta categoria também é menor, o que pode viabilizar o sistema produtivo.

Não foram detectadas diferenças $(\mathrm{P}>0,05)$ na taxa de eficiência protéica, porém, os machos não-castrados apresentaram superioridade numérica de 14,4 e 2,5\%, respectivamente, em relação aos castrados e às fêmeas. Considerando que a proteína é o nutriente de maior custo na alimentação e que representa a maior parte do custo de produção em sistemas de confinamento, esse diferencial pode representar lucro ou prejuízo da atividade.

Os machos não-castrados apresentaram ganho de área de olho-de-lombo $28 \%$ superior ao dos machos castrados e ao das fêmeas, o que está relacionado à prioridade de deposição de tecidos corporais, pois, como relatado por Luchiari Filho (2000), os animais não-castrados apresentam taxa de crescimento muscular mais acentuada em comparação aos castrados e às fêmeas (Tabela 5).
Os animais apresentaram peso similar ao início do experimento, não sendo detectadas diferenças $(\mathrm{P}>0,05)$, o que pode estar relacionado à curta duração da estação de parição (60 dias) e ao fornecimento de alimentação controlada na fase de recria a fim de preparar os animais para o confinamento e reduzir os possíveis efeitos de ganho compensatório ao início da fase experimental.

Os animais não-castrados foram mais pesados $(\mathrm{P}<0,05)$ ao final do experimento, como resultado do melhor ganho de peso durante o período de confinamento. Não foram observadas diferenças no peso de abate quando considerado o efeito das dietas testadas $(\mathrm{P}>0,05)$. Mesmo com maior peso de abate, os machos não-castrados não diferiram dos demais animais quanto ao rendimento de carcaça. Do mesmo modo, as dietas também não influenciaram essa variável.

Brondani et al. (2006) observaram pesos de abate de 421,3 e 422,6 kg e rendimentos de carcaça quente de 50,7 e $52,7 \%$ em novilhos Charolês alimentados com dietas à base de cana-de-açúcar ou silagem de milho, respectivamente. Esses autores observaram que, em virtude da menor digestibilidade em relação à silagem de milho, a cana-deaçúcar permaneceu por mais tempo no trato digestório, ocasionando maior volume ruminal e interferindo negativamente no rendimento de carcaça. Os resultados deste estudo não confirmam essas observações.

Os resultados obtidos nos machos não-castrados para área de olho-de-lombo foram superiores $(\mathrm{P}<0,05)$ em relação aos encontrados nas fêmeas, porém, os machos castrados apresentaram valor intermediário e não diferiram dos outros grupos. Não houve efeito das dietas $(\mathrm{P}>0,05)$ sobre a área 
Tabela 5 - Pesos inicial $(\mathrm{kg})$ e de abate (PA, kg), rendimento de carcaça (RC, \% PA), pesos da carcaça quente (kg) e resfriada (PR, kg), área de olho-de-lombo ( $\mathrm{cm}^{2}$ e $100 \mathrm{~kg}$ de carcaça fria, AOL\%) e espessura de gordura de cobertura (EGC, mm) de bovinos Canchim de diferentes condições sexuais alimentados com dietas à base de silagem de milho e concentrado ou cana-de-açúcar e concentrado contendo grãos de girassol ${ }^{1}$

Table 5 - Initial $(\mathrm{kg})$ and slaughter (SW, $\mathrm{kg}$ ) weights, carcass yield (CY, \%SW), hot ( $\mathrm{HCW}, \mathrm{kg})$ and cold (CCW, $\mathrm{kg})$ carcass weights, rib eye area (cm² and to $100 \mathrm{~kg}$ of cold carcass, REA \%), and backfat thickness (BT, $\mathrm{mm}$ ) by Canchim cattle of different sexual categories fed corn silage and concentrate based diet or sugar cane and concentrate containing sunflower grains

\begin{tabular}{|c|c|c|c|c|c|c|c|c|}
\hline \multirow[t]{2}{*}{ Item } & \multicolumn{3}{|c|}{$\begin{array}{c}\text { Condição sexual } \\
\text { Sexual category }^{1}\end{array}$} & \multirow[b]{2}{*}{$\mathrm{F}$} & \multicolumn{2}{|c|}{$\begin{array}{c}\text { Dieta }^{2} \\
\text { Diet }\end{array}$} & \multirow[b]{2}{*}{$\mathrm{F}$} & \multirow[b]{2}{*}{ CV (\%) } \\
\hline & $\begin{array}{l}\mathrm{MNC} \\
I M\end{array}$ & $\begin{array}{l}\mathrm{MC} \\
\mathrm{CM}\end{array}$ & $\begin{array}{l}\mathrm{FM} \\
F M\end{array}$ & & $\begin{array}{l}\text { SIL } \\
\text { CS }\end{array}$ & $\begin{array}{l}\text { CNA } \\
\text { SC }\end{array}$ & & \\
\hline $\begin{array}{l}\text { Peso inicial } \\
\text { Initial weight }\end{array}$ & 295,6 & 290,1 & 280,5 & NS & 293,33 & 284,13 & NS & 5,77 \\
\hline $\begin{array}{l}\text { Peso abate } \\
\text { Slaughter weight }\end{array}$ & $468,8 \mathrm{a}$ & $427,2 b$ & $416,8 b$ & * & 443,06 & 432,13 & NS & 6,21 \\
\hline $\begin{array}{l}\text { Peso carcaça quente } \\
\text { Hot carcass weight }\end{array}$ & $253,85 a$ & $229,50 b$ & $220,60 b$ & $*$ & 229,16 & 240,17 & NS & 7,29 \\
\hline $\begin{array}{l}\text { Peso carcaça fria } \\
\text { Cold carcas weight }\end{array}$ & $231,88 a$ & $208,32 b$ & $198,55 b$ & * & 207,28 & 218,55 & NS & 8,16 \\
\hline $\begin{array}{l}\text { Área de olho-de-lombo (AOL) } \\
\text { Rib eye area (REA) }\end{array}$ & $82,64 a$ & $73,95 \mathrm{ab}$ & $71,15 b$ & $*$ & 77,28 & 74,55 & NS & 10,35 \\
\hline
\end{tabular}

${ }^{1}$ Médias, na linha, seguidas de letras diferentes diferem pelo $(P<0,05)$ teste Tukey (Means followed by different letter in a row differ $[P<0.05]$ by Tukey test).

$2 \mathrm{SIL}=$ dieta convencional à base de silagem de milho e concentrado; CNA = dieta à base de cana-de-açúcar e concentrado contendo grãos de girassol (CS = conventional corn silage and concentrate based diet; SC = sugar cane and concentrate containing sunflower grains).

de olho-de-lombo. Quando avaliada em relação ao rendimento de carcaça fria (AOL\%), a área de olho-de-lombo não diferiu $(\mathrm{P}>0,05)$ entre os animais, porém, a dieta com cana-de-açúcar proporcionou valor $9,15 \%$ superior $(\mathrm{P}<0,05)$ em relação àquela com silagem de milho. Apesar de a ingestão de PB não ter diferido $(\mathrm{P}>0,05)$ entre as dietas, em valores absolutos, os animais alimentados com a dieta CNA ingeriram, em média, $0,1 \mathrm{~kg}$ ou $7,63 \%$ mais $P B$ que aqueles alimentados com a dieta SIL, o que pode ter ocasionado esta diferença na AOL estimada em relação a $100 \mathrm{~kg}$ de carcaça fria.

Brondani et al. (2006) avaliaram a AOL na altura da $12^{\mathrm{a}}$ costela e observaram médias de 67,5 e $64,3 \mathrm{~cm}^{2}$ e de 31,6 e 29,2 por $100 \mathrm{~kg}$ de carcaça fria em novilhos Charolês alimentados com dietas à base de cana-de-açúcar e silagem de milho, respectivamente, terminados em confinamento.

Vaz et al. (2001) avaliaram animais cruzados e mestiços Charolês $\times$ Nelore e observaram valores de AOL de 60,50 e $66,3 \mathrm{~cm}^{2}$, respectivamente, para animais castrados ou nãocastrados. Os animais foram abatidos com menor peso e, conseqüentemente, apresentaram menor peso de carcaça, o que justifica os resultados inferiores.

Não foram detectadas diferenças $(\mathrm{P}>0,05)$ quanto ao acabamento de carcaça, representado pela espessura de gordura subcutânea. Esta variável é adequada para todas as condições sexuais e dietas avaliadas, visto que a exigência dos frigoríficos é de no mínimo 3 mm de gordura subcutânea.
Vaz \& Restle (2005) trabalharam com novilhos Hereford e obtiveram valores de espessura de gordura subcutânea de 5,17 e 4,91 mm em animais alimentados com dietas com canade-açúcar e silagem de milho, respectivamente. No trabalho de Brondani et al. (2006), novilhos Charolês alimentados com cana-de-açúcar ou silagem de milho, respectivamente, apresentaram 2,40 e 2,46 mm de espessura de gordura subcutânea.

Os valores obtidos neste trabalho para essa variável estão relacionados ao elevado valor energético das dietas e provavelmente ao efeito do genótipo da raça Canchim utilizada, que caracteriza maior precocidade de deposição de gordura subcutânea em comparação às raças européias continentais puras.

Conforme relatado por Cruz (1997), a deposição de gordura subcutânea nas carcaças pode ser influenciada pelo efeito de ganho compensatório, mas, nessa situação, verifica-se tendência de continuidade do crescimento e, portanto, a deposição de gordura subcutânea é menor, o que provavelmente não ocorreu neste estudo, pois a alimentação foi controlada nas fases de recria e préexperimental.

De acordo com Sampaio et al. (1998), grande parte dos trabalhos de pesquisa com bovinos encontra-se dissociada de uma análise econômica que possa balizar a tomada de decisões quanto à adoção de uma tecnologia ou estratégia de alimentação no processo produtivo. 
Apenas os machos não-castrados alimentados com a dieta à base de silagem de milho apresentaram receita diária quando avaliada a relação entre custo de produção diário e ganho de peso diário em arrobas de carcaça (Tabela 7). As demais dietas tornaram-se viáveis somente com a valorização do preço da arroba dos animais durante o período estudado.

As remunerações obtidas com os animais alimentados com a dieta com silagem de milho, representadas pela TRM, foram superiores às principais aplicações disponíveis no mercado financeiro. Embora com valores inferiores, a TRM obtida com os animais alimentados com dietas à base de cana-de-açúcar foi também positiva. A utilização de machos castrados apresentou pior resultado, pois a TRM obtida foi inferior ao rendimento da poupança $(0,63 \%$ a.m.), aplicação financeira mais comum. Esse resultado é reflexo do maior custo da dieta, do valor de aquisição do animal e do desempenho.

Sampaio et al. (1998) avaliaram economicamente o crescimento e a terminação de mestiços Canchim (machos não-castrados) em confinamento alimentados com dietas à base de silagem de milho e concentrado contendo diferentes fontes protéicas e obtiveram ao final do experimento, receita líquida média de R\$ 35,10 e TRM média de 1,65\% a.m., valores superiores apenas ao observado nos machos castrados alimentados com a dieta CNA. Ressalta-se que os animais permaneceram em confinamento durante 168 dias (recria e engorda), o que elevou os custos de produção.

No trabalho desenvolvido por Sampaio et al. (2002), em que machos $3 / 4$ Canchim x 1/4 Nelore, não-castrados, foram alimentados em confinamento com dietas à base de silagem de milho durante 84 dias, a receita líquida média foi de $\mathrm{R} \$ 124,34$ e a TRM de 5,6\%, evidenciando que o tempo de confinamento é relevante na composição dos custos e na determinação da rentabilidade da exploração.

Portanto, o preço de aquisição dos animais é um dos principais fatores que determinam a lucratividade. Assim, a utilização de fêmeas de raças destinadas à produção de carne pode ser uma alternativa, pois esses animais apresentam menor preço de arroba ao início do confinamento e desempenho bastante satisfatório, apesar dos descontos (em torno de 15\%) na comercialização de suas carcaças.

O uso de estratégias nutricionais com os objetivos de acelerar o ciclo produtivo, produzir animais mais jovens e, conseqüentemente, obter produtos com características e qualidades diferenciadas pode acarretar custos de produção

Tabela 6 - Avaliação do custo das dietas experimentais $(\mathrm{R} \$ / \mathrm{kg})$

Table 6 - Evaluation of costs of the experimental diet

\begin{tabular}{|c|c|c|c|c|c|}
\hline \multirow[t]{3}{*}{$\begin{array}{l}\text { Alimento } \\
\text { Feed }^{2}\end{array}$} & \multirow[b]{3}{*}{$\mathrm{R} \$^{3} / \mathrm{kg}$} & \multicolumn{4}{|c|}{$\begin{array}{l}\text { Dieta }^{1} \\
\text { Diet }^{1}\end{array}$} \\
\hline & & \multicolumn{2}{|c|}{$\begin{array}{l}\text { SIL } \\
C S\end{array}$} & \multicolumn{2}{|c|}{$\begin{array}{l}\text { CNA } \\
\text { SC }\end{array}$} \\
\hline & & $\begin{array}{c}\text { Quantidade/kg } \\
\text { Amount }\end{array}$ & $\mathrm{R} \$$ & $\begin{array}{c}\text { Quantidade/kg } \\
\text { Amount }\end{array}$ & $\mathrm{R} \$$ \\
\hline $\begin{array}{l}\text { Cana-de-açúcar } \\
\text { Sugar cane }\end{array}$ & 0,035 & 0,000 & 0,000 & 0,610 & 0,0214 \\
\hline $\begin{array}{l}\text { Silagem de milho } \\
\text { Corn silage }\end{array}$ & 0,050 & 0,644 & 0,032 & 0,000 & 0,0000 \\
\hline $\begin{array}{l}\text { Farelo de soja } \\
\text { Soybean meal }\end{array}$ & 0,440 & 0,060 & 0,026 & 0,075 & 0,0330 \\
\hline $\begin{array}{l}\text { Girassol em grão } \\
\text { Sunflower seed }\end{array}$ & 0,600 & 0,000 & 0,000 & 0,070 & 0,0420 \\
\hline $\begin{array}{l}\text { Milho } \\
\text { Corn }\end{array}$ & 0,230 & 0,180 & 0,041 & 0,150 & 0,0345 \\
\hline $\begin{array}{l}\text { Polpa cítrica } \\
\text { Dried citrus pulp }\end{array}$ & 0,200 & 0,070 & 0,014 & 0,065 & 0,0130 \\
\hline $\begin{array}{l}\text { Uréia } \\
\text { Urea }\end{array}$ & 0,800 & 0,002 & 0,002 & 0,002 & 0,0016 \\
\hline $\begin{array}{l}\text { Núcleo mineral } \\
\text { Mineral premix }\end{array}$ & 0,533 & 0,005 & 0,003 & 0,005 & 0,0027 \\
\hline $\begin{array}{l}\text { Bicarbonato de sódio } \\
\text { Sodium bicarbonate }\end{array}$ & 1,500 & 0,007 & 0,011 & 0,007 & 0,0105 \\
\hline Total & & 1,0 & 0,13 & 1,0 & 0,16 \\
\hline
\end{tabular}

${ }^{1} \mathrm{SIL}=$ dieta convencional à base de silagem de milho e concentrado; CNA = dieta à base de cana-de-açúcar e concentrado contendo grãos de girassol (CS = conventional corn silage and concentrate based diet; SC = sugar cane and concentrate containing sunflower grains).

2 Preços de mercado em R $\$ / \mathrm{kg}$ do ingrediente em março de 2006 (Market prices in $R \$ / \mathrm{kg}$ of ingredient in March 2006).

${ }^{3}$ US $\$ 1,00=\mathrm{R} \$ 2,15$. 
Tabela 7 - Viabilidade econômica da terminação de bovinos Canchim em confinamento de diferentes condições sexuais alimentados com dietas à base de silagem de milho e concentrado ou cana-de-açúcar e concentrado contendo grãos de girassol

Table 7 - Economic viability evaluation of the termination of Canchim cattle of different sexual categories fed corn silage and concentrate based diet or sugar cane and concentrate containing sunflower grains

\begin{tabular}{|c|c|c|c|c|c|c|c|}
\hline \multirow[b]{3}{*}{$\begin{array}{l}\text { Item de } \text { custo }^{2} \\
\text { Cost item }\end{array}$} & \multicolumn{7}{|c|}{$\begin{array}{c}\text { Dieta }^{1} \\
\text { Diet }\end{array}$} \\
\hline & \multicolumn{4}{|c|}{$\begin{array}{c}\text { CNA } \\
S C\end{array}$} & \multicolumn{3}{|c|}{$\begin{array}{l}\text { SIL } \\
\text { CS }\end{array}$} \\
\hline & $\begin{array}{r}\text { Macho } \\
Y\end{array}$ & $\begin{array}{l}\text { não-castrado } \\
\text { Young bull }\end{array}$ & $\begin{array}{l}\text { Macho castrado } \\
\text { Castrated male }\end{array}$ & $\begin{array}{l}\text { Fêmea } \\
\text { Female }\end{array}$ & $\begin{array}{c}\text { Macho não-castrado } \\
\text { Young bull }\end{array}$ & $\begin{array}{l}\text { Macho castrado } \\
\text { Castrated male }\end{array}$ & $\begin{array}{l}\text { Fêmea } \\
\text { Female }\end{array}$ \\
\hline Custo do animal (Animal cost) & & 426,82 & 418,75 & 357,22 & 424,51 & 416,74 & 327,20 \\
\hline Mecanização (Mechanization) & & 6,60 & 6,60 & 6,60 & 6,60 & 6,60 & 6,60 \\
\hline Mão-de-obra (Labor) & & 6,80 & 6,80 & 6,80 & 6,80 & 6,80 & 6,80 \\
\hline Medicamento (Medication) & & 3,46 & 3,46 & 3,46 & 3,46 & 3,46 & 3,46 \\
\hline Depreciação (Depreciation) & & 4,40 & 4,40 & 4,40 & 4,40 & 4,40 & 4,40 \\
\hline Administração (Administration) & & 7,98 & 7,98 & 7,98 & 7,98 & 7,98 & 7,98 \\
\hline Total & & 712,00 & 688,68 & 614,82 & 821,34 & 768,62 & 648,75 \\
\hline Peso entrada (Initial weight) (kg & & 296,4 & 290,8 & 292,8 & 294,8 & 289,4 & 268,2 \\
\hline @ inicial (@initial) & & 10,8 & 10,5 & 10,5 & 10,6 & 10,3 & 9,3 \\
\hline Rendimento carcaça (Carcass yie & eld) $(\%)$ & 54,52 & 54,3 & 53,84 & 53,74 & 53,14 & 51,94 \\
\hline Peso abate (Slaughter weight) (l & & 467,4 & 429,6 & 432,2 & 470,2 & 424,8 & 401,4 \\
\hline GMD (DWG) $(\mathrm{kg})^{4}$ & & 1,6 & 1,3 & 1,3 & 1,7 & 1,3 & 1,3 \\
\hline GMD (@) (DGW (@) & & 0,06 & 0,05 & 0,05 & 0,06 & 0,05 & 0,05 \\
\hline Custo diário (Daily cost) $(\mathrm{R} \$)^{5}$ & & 2,72 & 2,57 & 2,45 & 3,78 & 3,35 & 3,06 \\
\hline \multicolumn{8}{|l|}{$\begin{array}{l}\text { Viabilidade econômica } \\
\text { Economic viability }\end{array}$} \\
\hline Receita diária (Daily income) (R & R\$/@) & 3,06 & 2,48 & 2,40 & 3,13 & 2,36 & 2,25 \\
\hline Carcaça (Carcass) (@) & & 17 & 16 & 16 & 17 & 15 & 14 \\
\hline Receita bruta (Income) (R\$) & & 883,40 & 808,68 & 775,65 & 875,98 & 782,56 & 694,96 \\
\hline
\end{tabular}

${ }^{1} \mathrm{SIL}=$ dieta convencional à base de silagem de milho e concentrado; CNA = dieta à base de cana-de-açúcar e concentrado contendo grãos de girassol (CS = conventional corn silage and concentrate based diet; SC = sugar cane and concentrate containing sunflower grains).

2 Custo do animal = R \$1,44/kg para machos e R\$1,22/kg para fêmeas; mecanização, medicamentos, mão-de-obra, depreciação e administração (Anualpec, 2005) (Animal cost $=R \$ 1.44 / \mathrm{kg}-$ males and $R \$ 1.22=$ females; mechanization, labor, medications, depreciation and administration (Anualpec, 2005).

$3 \mathrm{GMD}=$ ganho médio diário (DGW = Daily weight gain).

${ }^{4}$ US $\$ 1,00=\mathrm{R} \$ 2,15$; @ macho = R $\$ 52,00$; @ fêmea $=\mathrm{R} \$ 50,00$ (março de 2006) (US\$1.00=R\$2.15; @ male = R $\$ 52.00 ; @$ female = R $\$ 50.00$, March 2006).

$5 \mathrm{TRM}=$ taxa de remuneração mensal, $\%$ ao mês $(M R T=$ monthly remuneration tax, \% at month).

mais elevados. Nesse sentido, o pagamento ao produtor com base apenas no peso de carcaça pode inviabilizar a adoção de novas técnicas de manejo e alimentação que poderiam contribuir para a melhoria da qualidade dos produtos cárneos.

O modelo de produção intensiva de carne, nesse caso representado pela engorda de animais em confinamento, possibilitou, em geral, resultados positivos, comprovando que a atividade pode ser lucrativa. Deve ser avaliado ainda o contexto do sistema de produção, pois essa estratégia de terminação de bovinos pode proporcionar benefícios indiretos, como aumento da produtividade da propriedade, diluição de custos fixos, liberação de áreas de pastagens para outras categorias e emprego de novas tecnologias.

\section{Conclusões}

Os machos não-castrados apresentam maior ingestão de nutrientes, maior ganho de peso, maior área de olho-de-lombo e são mais eficientes quanto ao ganho de peso, sendo indicados para utilização em sistemas de produção de bovinos jovens em confinamento. Novilhas de raças de corte apresentam bom desempenho e podem ser uma alternativa para a exploração intensiva em confinamento. A utilização da variedade de cana-de-açúcar forrageira IAC86-2480, associada a concentrado contendo sementes de girassol, apresenta bom potencial para utilização em sistemas de confinamento. Contudo, na formulação da dieta, é necessário atentar para o não comprometimento dos custos com alimentação. 


\section{Agradecimento}

Ao Instituto Agronômico de Campinas - IAC, pelo fornecimento das mudas de cana-de-acúcar forrageira IAC 86-2480, utilizadas na formação do canavial experimental.

À Embrapa Pecuária Sudeste, pelo colaboração na execução deste trabalho.

\section{Literatura Citada}

ANUALPEC 2005. Anuário da pecuária brasileira. São Paulo: FNP Consultoria e Comércio, 2005. 340p.

ASSOCIATION OF OFFICIAL ANALYTICAL CHEMISTS - AOAC. Official methods of analysis. 16.ed. Washington, D.C.: 1995. 1011p.

BETT, V. Grãos de girassol em rações para vacas leiteiras. Jaboticabal: Universidade Estadual Paulista, 2002. 115p. Tese (Doutorado em Zootecnia) - Universidade Estadual Paulista, 2002.

BRONDANI, I. Desempenho e características de carcaça de bovinos jovens. Jaboticabal: Universidade Estadual Paulista, 2002. 133p. Tese (Doutorado em Zootecnia) - Universidade Estadual Paulista, 2002.

BRONDANI, I.; RESTLE, J.; ARBOITTE, M.Z. et al. Efeito de dietas que contém cana-de-açúcar ou silagem de milho sobre as características das carcaças de novilhos confinados. Ciência Rural, v.36, n.1, p.197-202, 2006.

BURGÜI, R. Confinamento estratégico. In: MATTOS, W.R.S. (Ed.) A produção animal na visão dos brasileiros. Piracicaba: Fundação de Estudos Agrários Luis de Queiroz, 2001. 927p.

CARDOSO, G.C.; GARCIA, R.; SOUZA, A.L. et al. Desempenho de novilhos Simental alimentados com silagem de sorgo, cana-de-açúcar ou palhada de arroz tratada ou não com amônia anidra. Revista Brasileira de Zootecnia, v.33, n.6, p.2132-2139, 2004 (supl. 2).

CHURCH, D.C. El rumiante: fisiologia digestiva e nutricion. Zaragoza: Acribia, 1988. 640p.

CONFEDERAÇÃO NACIONAL DA AGRICULTURA E PECUÁRIA DO BRASIL - CNA. Indicadores rurais. Brasília, n.58, p.1-6, 2005.

CRUZ, G.M. Terminação do bovino jovem em confinamento. In: CONVENÇÃO NACIONAL DA RAÇA CANCHIM, 3., 1997, São Carlos. Apostila... São Carlos: Embrapa - Centro de Pesquisa de Pecuária do Sudeste, 1997. 108p.

EUCLIDES FILHO, K. O enfoque de cadeia produtiva como estratégia para a produção sustentável de carne bovina. In: MEDEIROS, S.R.; EUCLIDES FILHO, K.; EUCLIDES, V.P.B. (Eds.) A produção animal e a segurança alimentar. Campo Grande: Sociedade Brasileira de Zootecnia, 2004. 568p.

FERNANDES, A.R.M.; SAMPAIO, A.A.M.; CERQUEIRA, A.A. et al. Recria de bezerras Canchim alimentadas com dietas contendo cana-de-açúcar e diferentes relações PDR:NDT. Ars Veterinária, v.20, n.3, p.256-265, 2004.

FOX, D.G.; SNIFFEN, C.J.; O'CONNOR, J.D. A net carbohydrate and protein system for evaluating cattle diets: III. Cattle requirements and diets adequacy. Journal of Animal Science, v.70, n.6, p.3578-3596, 1992.

HERNANDEZ, M.R. Desempenho e digestibilidade aparente de variedades de cana-de-açúcar com bovinos. Jaboticabal, 1998. 69p. Dissertação (Mestrado em Zootecnia) - Universidade Estadual Paulista, 1998.

LANDELL, M.G.A.; CAMPANA, M.P.; RODRIGUES, A.A. et al. A variedade IAC84-2480 como nova opção de cana-de-açúcar para fins forrageiros: manejo de produção e uso na alimentação animal. Campinas: Instituto Agronômico, 2002. 39p. (Boletim Técnico, 193).
LUChIARI FILHO, A. A pecuária da carne bovina. São Paulo: Binlife, 2000. 134p.

MACEDO, M.P.; BASTOS, J.F.P; BIANCHINI SOBRINHO, E. et al. Característica de carcaça e composição corporal de touros jovens da raça Nelore terminados em diferentes sistemas. Revista Brasileira de Zootecnia, v.30, n.5, p.1610-1620, 2001.

MANZANO, A.; ESTEVES, S.N.; FREITAS, A.R. et al. Eficiência de utilização de nutrientes em novilhas das raças Canchim e Nelore e cruzadas Canchim x Nelore. Revista Brasileira de Zootecnia, v.28, n.6, p.1375-1381, 1999.

NATIONAL RESEARCH COUNCIL - NRC. Nutrient requirements of beef cattle. 7.ed. Washington: National Academy Press, 1996. 242p.

PADUA, J.; SAINZ, R.D.; PRADO, C.S. et al. Efeitos de grupos genéticos, castração e anabolizantes no desempenho e nas carcaças de bovinos de corte. In: REUNIÃO ANUAL DA SOCIEDADE BRASILEIRA DE ZOOTECNIA, 38., 2001, Piracicaba. Anais... Piracicaba: Sociedade Brasileira de Zootecnia, 2001. p.1518-1519.

RESTLE, J.; FELTEN, H.G.; VAZ, F.N. Efeito de raça e heterose para desempenho em confinamento. In: REUNIÓN LATINOAMERICANA DE PRODUCCION ANIMAL, 14. 1995, Mar del Plata. Anais... Balcarce: Associación Latinoamericana de Producción Animal, 1995. p.852-854.

RESTLE, J.; NEUMANN, M.; ALVES FILHO, D.C. et al. Terminação em confinamento de vacas e novilhas sob dietas com ou sem monensina sódica. Revista Brasileira de Zootecnia, v.30, n.6, p.1801-1812, 2001.

RLM 2.0 - Ração de Lucro Máximo. Versão 2.0. Piracicaba: Departamento de Zootecnia, 1999. (CD-ROM).

SAMPAIO, A.A.M.; BRITO, R.M.; CARVALHO, R.M. Comparação de sistemas de avaliação de dietas para bovinos no modelo de produção intensivo de carne. Confinamento de tourinhos jovens. Revista Brasileira de Zootecnia, v.31, n.1, p.157-163, 2002.

SAMPAIO, A.A.M.; BRITO, R.M.; VIEIRA, P.F. et al. Efeito da suplementação protéica sobre o crescimento, terminação e viabilidade econômica de bezerros mestiços Canchim confinados pós-desmama. Revista Brasileira de Zootecnia, v.27, n.4, p.823-831, 1998.

SAMPAIO, I.B.M. Estatística aplicada à experimentação animal. 2.ed. Belo Horizonte: Fundação de Estudos e Pesquisas em Medicina Veterinária e Zootecnia, 2002. 265p.

SILVA, T.M.; OLIVEIRA, M.D.S; SAMPAIO, A.A.M. et al. Efeito da hidrólise de diferentes variedades de cana-de-açúcar sobre a digestibilidade ruminal "in vitro". In: REUNIÃO ANUAL DA SOCIEDADE BRASILEIRA DE ZOOTECNIA, 42., 2005 , Goiânia. Anais... Goiânia: Sociedade Brasileira de Zootecnia, 2005. (CD-ROM).

TULLIO, R.R. Estratégias de manejo para produção intensiva de bovinos visando à qualidade da carne. Jaboticabal: Universidade Estadual Paulista, 2004. 107p. Tese (Doutorado em Zootecnia) - Universidade Estadual Paulista, 2004.

VAZ, F.N.; RESTLE, J.; BRONDANI, I. et al. Qualidade e composição química da carne de bovinos de corte inteiros ou castrados de diferentes grupos genéticos Charolês $x$ Nelore. Revista Brasileira de Zootecnia, v.30, n.2, p.518-525, 2001.

VAZ, F.N.; RESTLE, J. Características de carcaça e da carne de novilhos Hereford, terminados em confinamento com diferentes fontes de volumoso. Revista Brasileira de Zootecnia, v.34, n.1, p.230-238, 2005. 